\section{Depression and geriatric assessment in older people admitted for hip fracture}

\author{
SERGIO CHARLES-LOZOYA ${ }^{1, a}$, HÉCTOR COBOS-AGUILAR ${ }^{2, a}$, \\ ELIZABETH BARBA-GUTIÉRREZ ${ }^{\mathrm{b}}$, JESÚS MIGUEL \\ BRIZUELA-VENTURA ${ }^{3}$, SALVADOR CHÁVEZ-VALENZUELA ${ }^{3}$, \\ ADRIÁN GARCÍA HERNÁNDEZ ${ }^{3}$, JUAN CARLOS TAMEZ MONTES ${ }^{3}$
}

\section{ABSTRACT}

Background: Depression is common among older people with hip fracture. Aim: To assess depression scores and other mental and physical health variables in older people with and without depression, admitted to a traumatology ward for a hip fracture. Material and Methods: Cross sectional study of older patients admitted for surgical treatment of hip fracture. Demographic, clinical and laboratory variables were recorded. Twelve surveys were applied to assess general wellbeing, mental health, fall risk, nutritional status, basic and instrumental activities of daily living, social resources and depression (using Yesavage Depression Scale). Results: We assessed 310 patients aged 78 (72-83) years, $72 \%$ women. Overall depression prevalence was $46 \%$ and its frequency was significantly higher in women, people over 81 years of age, diabetics and subjects with anxiety. The Yesavage score in patients with and without depression was 6.5 and 3 , respectively. The median number of medications used by patients with and without depression was 3 and $2(p<0.01)$. Conclusions: There is a high frequency of depression in these patients, especially in women and subjects older than 81 years of age. Routine geriatric assessments should be performed in hospitalized older patients with hip fracture.

(Rev Med Chile 2019; 147: 1005-1012)

Key words: Anxiety; Depression; Geriatric Assessment; Hip Fractures.

\section{Depresión y evaluación geriátrica en adultos mayores ingresados por fractura de cadera}

Antecedentes: La alta prevalencia de depresión en la población anciana con fractura de cadera rara vez se reconoce. Objetivo: Estimar la prevalencia de depresión y comparar la salud física, mental, y otras variables geriátricas, en ancianos hospitalizados por fractura de cadera con y sin depresión. Material y Métodos: Estudio transversal con muestreo probabilístico con reemplazo, de pacientes que ingresaron para su atención quirúrgica. Se recolectaron variables sociodemográficas, antropométricas, clínicas y de laboratorio. Se aplicaron 12 encuestas para evaluar el estado de salud general, mental, riesgo de caídas, estado nutricional, actividades básicas e instrumentadas de la vida diaria, recursos sociales y depresión, entre otras. Para detectar depresión se usó la escala de tamizaje de Depresión Geriátrica Yesavage (EDG-15). Resultados: Se revisaron 310 pacientes (grupos con y sin depresión). La prevalencia de depresión fue de 46\%,
${ }^{1}$ Health Science Education, Hospital de Traumatología y Ortopedia No. 21, Instituto Mexicano del Seguro Social (IMSS). Monterrey, N.L., México ${ }^{2}$ Health Science Division, Vicerectory of Health Science, Universidad de Monterrey, San Pedro Garza García, N.L., México. ${ }^{3}$ Hip and Pelvic Unit, Unidad Médica de Alta Especialidad (UMAE), Hospital de Traumatología y Ortopedia No. 21, Instituto Mexicano del Seguro Social (IMSS). Monterrey, NL.,

México.

${ }^{\mathrm{a} M . S \mathrm{C} .}$

${ }^{\mathrm{b}}$ Health Science Division, Medical Student, Universidad de Monterrey, Monterrey, NL, Mexico; Human Nutrition and Foods (RD), University of Houston, Houston, TX. United States od America.

The corresponding authors declare no conflict of interest. Financing: Authors did not receive any financing for this research.

Recibido el 15 de marzo de 2019 aprobado el 30 de julio de 2019.

Corresponding author: Sergio Charles Lozoya M.Sc. Av. José Ma. Pino Suárez y Juan Ignacio Ramón $\mathrm{s} / \mathrm{n}, 10^{\circ}$ piso. Col. Centro. C.P. 64000 Monterrey, NL., México. scharleslozoya@yahoo.com.mx 
significativamente mayor en mujeres, sujetos mayores de 81 años, diabéticos y aquellos con ansiedad. La mediana de la puntuación EDG-15 fue de 6,5 y 3 para sujetos con y sin depresión $(n=142),(n=168)$, respectivamente. La mediana del número de fármacos fue de 3 y 2 en estos grupos $(p<0,01)$. Conclusiones: $L a$ evaluación geriátrica sistemática en la atención del adulto mayor con fractura de cadera es indispensable, lo que podría aumentar las tasas de detección de depresión y de otros padecimientos e impactar positivamente en la calidad de vida y restauración de la función.

Palabras clave: Ansiedad; Evaluación Geriátrica; Fracturas de Cadera.

$\mathrm{D}$ epression is a common disorder and a cause of disability, affecting 120 million people around the world ${ }^{1}$. In subjects above 60 years of age, major depression is common; increases with comorbidities between 5 and $10 \%$ and rises to $37 \%$ after hospitalization due to serious illness ${ }^{2}$. It is a prevalent comorbidity in older adults (OA) with hip fracture (HF). It is estimated that it ranges between 9 and $47 \%{ }^{3}$. It occurs in subjects with physical conditions such as $\mathrm{OA}$ hospitalized, associated with inadequate results, longer in-hospital stay and higher mortality rate; in OA, it can increase the risk of falls with subsequent $\mathrm{HF}$ and poor cooperation for rehabilitation, and even more, if depressive symptoms persist after HF because they are associated with physical malfunction ${ }^{4}$. Depression in patients with fracture sequels is associated with a lower quality of life (QOL), greater use of health system services and increase in mortality ${ }^{5}$. Depression is a disability seen frequently in $\mathrm{OA}$ and is associated with adverse outcomes that include self-harm, premature mortality and comorbidities such as heart failure, stroke and obesity ${ }^{6}$. Likewise, social isolation is another risk factor in the development of depression in the last stages of life. Studies show clinical factors such as medical morbidity, functional limitations, cognitive deterioration and pain that correlate strongly with depression ${ }^{7}$. Studies conducted with OA patients found hospitalization to be a major risk factor for depression ${ }^{8}$ and that it is most common in a hospitalized elderly population with physical illnesses ${ }^{9}$.

On the other hand, HF is a major health problem. Its complications include chronic pain, disability, decreased QOL and premature death ${ }^{10}$; a patient with depression and HF may have higher functional disability and higher dependence ${ }^{11}$. Despite this being considered a relevant and frequent problem, there are very few reports of geriatric assessments to determine a depressive and functional status prior to HF in hospitalized patients. It is essential to correct this condition in all elderly patients, to be able to offer a positive impact on the restoration of function, well-being and QOL. The aim of this study was to estimate prevalence of depression, compare the physical and mental health, as well as other geriatric variables, in an elderly group, hospitalized for HF with or without depression.

\section{Materials and Methods}

A comparative survey was conducted, during 2017 in a regional hospital, specialized in Traumatology and Orthopedics of the Mexican Social Security Institute in Northeastern Mexico. The coexistence of depression and cognitive impairment increases the prevalence of depression, so individuals older than 65 years with HF (radiological diagnosis corroborated by two hip surgeons), without cognitive impairment (Mini Mental $\geq 24$ point) were included. Exclusions included: individuals under antidepressants treatment, use of antipsychotic medications, re-fracture and surgical wound infection.

Sample selection: from the register of daily admissions for hip service, using a random probability sampling with replacement and sample size for proportion in infinity population with similar characteristics and frequency of depression in hospitalized older adults of $29 \%{ }^{9}$ and $d: 0.05$ for 310 participants.

To register, participants were questioned directly for: age, gender, schooling, comorbidities (pulmonary, cardiovascular, urological, renal, liver disease, cancer, endocrinopathies and brain disease), economic support (pension, family or work), caregiver's gender, housing (own, rented, 
borrowed or temporary stay), sensory deprivation (visual or auditory), total of current medications, alcohol intake and smoking. Fasting venous blood samples were taken to determine glucose, hemoglobin, hematocrit, urea, creatinine, urea nitrogen, leukocytes and lymphocytes, processed by the Ilab 650 IL (Instrumentation Laboratory SpA. Milano, Italy). The second part of the questioning explored the measurement of the clinimetric variables of the geriatric evaluation before the HF occurred and included the following 12 scales: 1$)$ Yesavage $^{12}$ (15 question version), used for depression screening, hetero-administered, with ten affirmative items and five negative, score of $0-4$ are normal, 5-8 mild depression, 9-11 moderate depression, 12-15 severe depression, consistent (Cronbach's Alpha $0.86)$ and reproductible $\left.(r=0.81)^{13} ; 2\right)$ Inventory of social resources of an OA of Díaz-Veiga (ISR) ${ }^{14}$, values the social environment that supports the OA, through relationships: spouse, children, relatives and friends. When scored $\leq 17$ a support plan is recommended; 3) Instrumental Activities of Daily Living Scale (IADL) (modified Scale of Lawton and Brody), assesses five items: ability to use the telephone, use of transportation, shopping, responsibility for medication and management of their economy, the rating ranges between 0 (maximum dependence) and 5 (total independence) consistent (Cronbach's Alpha 0.94) ${ }^{15}$; 4) Basic activities of daily life (BADL) (Barthel Scale modified by Shah et al.), with ten items: personal hygiene, bathing, eating, using the toilet, climbing stairs, dressing, moving (walking on a smooth surface or in a wheelchair), transfer chair/bed, stool control and urine control. The results vary between 0 (completely dependent) and 100 points (completely independent), with $\kappa=0.77$ interobserver and $\kappa=0.85$ intraobserver $\left.{ }^{16} ; 5\right)$ The nutritional assessment was performed with the MNA (Mini Nutritional Assessment), hetero-administered, used as screening and consisting of six items, if a score is obtained $\leq 10$, then the evaluation takes place, if score is between 17 and 23.5 patient is in risk of malnourishment and $<17$ points, indicates malnutrition. (Cronbach's Alpha 0.83) and ICC: $0.89^{17}$; 6) Fragility was assessed with the Barber questionnaire, which contains nine items. Each affirmative answer is worth a point. One or more points suggest risk situation, sensitivity of 0.95 and specificity of 0.68 , PPV $0.91^{18}$; 7) The pain was measured with the visual analog scale (VAS), on a numerical scale from zero to ten, in which zero is absence and ten the maximum intensity of pain. The patient tells the number that best indicates that intensity, reliable $(r=0.94)$, useful even for illiterates $(r=0.71)^{19}$. It was applied twice, and the median was taken as the definitive one; 8) Insomnia was evaluated with the Insomnia Severity Index Scale (ISI) and consists of seven items, the score ranges from 0 (absence of insomnia) to 28 (severe insomnia), Cronbach's Alpha of 0.92 , sensitivity, specificity of $82.4 \%, 82.1 \%$, respectively ${ }^{20}$; 9) Abuse was analyzed with the screening questionnaire of the American Medical Association (AMA), which contains nine items, a positive response is considered suspicion of abu$\left.\mathrm{se}^{21} ; 10\right)$ The risk of pressure ulcers was evaluated with the Barden and Bergstrom scale, consisting of six items: sensory perception, exposure of the skin to moisture, physical activity, mobility, nutrition, friction and danger of skin lesions; a score between 6 and 12 qualifies as low, 13-18 medium and 19-24 high risk, respectively, specificity $70 \%$ and sensitivity $77 \%$;2, 11) Anxiety was screened with the Goldberg Anxiety and Depression Scale, with subscales for depression and anxiety, each with nine items of yes/no answers. The initial four items for screening and the other five are formulated when positive responses are obtained from the screening; (Cronbach's Alpha 0.65), sensitive $(83.1 \%)$ and specific $(81.8 \%)^{23}$. For the study, only the anxiety questionnaire was applied; 12) The risk of hospital falls was evaluated with the Scale of Risk Factors for Falls, that consists of five factors, fluctuates from zero to ten, qualifies the risk as low (0-1), medium (2-3) and high (4-10) with Cronbach's Alpha $0.99^{24}$.

These measures were applied between one to four days before undergoing surgery of the HF . They were applied by personnel unrelated to the study (two trained doctors), blindly and independently at the patient's bedside. All the data were directly taken from the patient, as well as caregivers, the inter-observer concordance was estimated for all the instruments. The protocol was previously authorized by the Local Research and Ethics Committee, No. 1903.

Prior to the study, weekly training meetings were held for those in charge of questioning the patients (two doctors), and they were instructed on the data collection instruments. The geriatric assessment was carried out by personnel specia- 
lized in geriatrics and psychiatry. A pilot test was conducted before the start of the study. Participants who met the selection criteria and wished to participate, were informed of objectives of the study and asked for their signed consent.

\section{Statistics}

Mann-Whitney $\mathrm{U}$ test to test non-parametric variables; Pearson's $\chi^{2}$ test to compare frequencies and percentages of dichotomous qualitative variables. RM (IC 0.95) was calculated for magnitude of association. A value of $p<0.05$ was considered significant. The analysis was carried out with the SPSS program version 22 (SPSS, Chicago, IL, USA).

\section{Results}

Four hundred and twenty-three participants were eligible to enter the study, and 310 participants were admitted. One hundred and thirteen did not meet the selection criteria, 50 because they were taking antidepressants and 63 had a cognitive impairment. The median age was 78 years, interquartile range (IQR), (72-83) and 224 were women $(72.3 \%)$. Depression and anxiety were detected in $45.8 \%$ and $38.1 \%$, respectively. The median score of the Yesavage scale, in the total population, was 4 points, (IQR: 2-6), in subjects with and without depression was 6.5 and 3 points, (IQR: $5-8$ ), (IQR: 2-4), respectively; only 21 subjects $(6.8 \%)$ presented $\geq 10$ points. (Table 1 ). From the comparison of geriatric variables and physical health, between subjects with and without depressive symptoms, $79.6 \%$ (113 participants) were women and $4.8 \%$ of the subjects had chronic renal failure. Most caregivers were female, in 223 subjects. Clinical factors were compared between patients with and without depression (Table 2); the characteristics with statistically significant differences $(p=0.001)$ were age, number of medications, hearing and visual deficit, gender, diabetes and abuse; of depressed patients, 53.5\% had diabetes and $65.5 \%$ had hypertension. In turn, we analyzed the results of the scale of evaluation of risk factors for falls between both groups; we found in 228 patients $(73.5 \%)$ a high risk of falling $(\mathrm{p}=0.03)$. When comparing the two groups and their laboratory results (Table 3 ), only glucose showed significant differences in those with depression. Also, between the two groups all the clinimetric variables showed statistically significant differences and in the scores of the ISR scales of Díaz-Veiga, of Lawton and Brody, MNA and Barthel, the result was $\mathrm{p}<0.001$, (Table 4). To compare both groups of the Barden risk scale to develop ulcers, $213(68.7 \%)$ were classified as high risk, but without significant differences.

\section{Table 1. Sociodemographic characteristics of the geriatric population and score of the Yesavage scale $(n=310)$. General population characteristics $(n=310)$}

\begin{tabular}{|c|c|c|}
\hline Characteristics & $\mathbf{n}$ & (\%) \\
\hline Age & 78 & $(72-83)^{*}$ \\
\hline \multicolumn{3}{|l|}{ Gender } \\
\hline Female & 224 & (72.3) \\
\hline Male & 86 & $(27.7)$ \\
\hline Depression & 142 & $(45.8)$ \\
\hline \multicolumn{3}{|l|}{ Punctuation DGS-15 } \\
\hline $0-4$ & 168 & $(54.2)$ \\
\hline $5-8$ & 108 & (34.8) \\
\hline $9-11$ & 27 & $(8.7)$ \\
\hline $12-15$ & 7 & $(2.3)$ \\
\hline Anxiety & 118 & $(38.1)$ \\
\hline Diabetes Mellitus & 141 & $(45.5)$ \\
\hline Systemic arterial hypertension & 185 & $(59.7)$ \\
\hline Comorbidities & 41 & $(13.2)$ \\
\hline Smoking & 9 & $(2.9)$ \\
\hline Alcohol ingestion & 8 & $(2.6)$ \\
\hline \multicolumn{3}{|l|}{ Schooling } \\
\hline Illiterate & 25 & $(8.1)$ \\
\hline$\leq 6$ years & 228 & $(73.5)$ \\
\hline$>6$ years & 57 & $(18.4)$ \\
\hline \multicolumn{3}{|l|}{ Civil status } \\
\hline Married & 141 & $(45.5)$ \\
\hline Single & 13 & $(4.2)$ \\
\hline Widowed & 144 & $(46.5)$ \\
\hline Divorced & 12 & (3.9) \\
\hline \multicolumn{3}{|l|}{ Economic status } \\
\hline Working & 12 & (3.8) \\
\hline Retired & 199 & $(64.2)$ \\
\hline Family & 99 & (31.9) \\
\hline \multicolumn{3}{|l|}{ Housing } \\
\hline Own & 291 & (93.9) \\
\hline Rent & 3 & $(0.9)$ \\
\hline Leased & 16 & $(5.2)$ \\
\hline
\end{tabular}

*Median and interquartile range. GDS-15: Geriatric depression scale (15-items). 
Depression and geriatric assessment for hip fracture - S. Charles-Lozoya et al

Table 2. Comparative analysis of characteristics in group of patients with hip fracture with or without depression

\begin{tabular}{|c|c|c|c|c|c|}
\hline Clinical variables & $\begin{array}{l}\text { With depression } \\
n=142(46 \%)\end{array}$ & $\begin{array}{l}\text { Without depression } \\
\quad n=168(54 \%)\end{array}$ & OR & Cl $95 \%$ & $\mathbf{p}$ \\
\hline Age & $81(75-86)^{*}$ & $71.0(76-82)^{\star}$ & - & - & $<0.001$ \\
\hline Female & $113(79.6 \%)$ & $111(66.1 \%)$ & 0.5 & $0.3-0.8$ & 0.008 \\
\hline Alcoholism & $4(2.8 \%)$ & $4(2.4 \%)$ & 1.2 & $0.3-4.8$ & 0.81 \\
\hline Smoking & $3(2.1 \%)$ & $6(3.6 \%)$ & 0.6 & $0.1-2.4$ & 0.45 \\
\hline Diabetes & $76(53.5 \%)$ & 65 (38.7\%) & 1.8 & $1.2-2.9$ & 0.009 \\
\hline $\mathrm{HBO}(\mathrm{mmHg})$ & $93(65.5 \%)$ & 92 (54.8\%) & 1.6 & $1.0-2.5$ & 0.55 \\
\hline Visual impairment & $41(28.9 \%)$ & $28(16.7 \%)$ & 2.0 & $1.2-3.5$ & 0.01 \\
\hline Hearing impairment & $57(40.1 \%)$ & $32(19.0 \%)$ & 2.8 & $1.7-4.7$ & $<0.001$ \\
\hline Anxiety & $71(50.0 \%)$ & $47(28.0 \%)$ & 2.6 & $1.6-4.1$ & $<0.001$ \\
\hline Abuse & 27 (19.0\%) & $15(8.9 \%)$ & 2.4 & $1.2-4.7$ & 0.01 \\
\hline Fragility & 103 (72.5\%) & $106(63.1 \%)$ & 1.5 & $0.9-2.5$ & 0.08 \\
\hline \multicolumn{6}{|l|}{ Fall risk } \\
\hline High & 95 (66.9\%) & $133(79.2 \%)$ & - & - & 0.03 \\
\hline Medium & $46(32.4 \%)$ & 29 (17.3\%) & - & - & \\
\hline Low & $1(0.7 \%)$ & $6(3.6 \%)$ & - & - & \\
\hline
\end{tabular}

*Median and an interquartile range. OR: Odds ratio. Cl: Confidence interval. HBP: High blood pressure.

Table 3. Laboratory characteristics of patients with hip fracture with and without depression

\begin{tabular}{|c|c|c|c|}
\hline Variables & $\begin{array}{l}\text { With depression } \\
n=142(46 \%)\end{array}$ & $\begin{array}{l}\text { Without depression } \\
\quad n=168(54 \%)\end{array}$ & $\mathbf{p}$ \\
\hline Glucose (mg/dL) & $134.5(118-156)$ & $123.5(109-146)$ & 0.007 \\
\hline BUN (mg/dL) & $22.35(18.7-33)$ & $21(16-31.9)$ & 0.61 \\
\hline Creatinine (mg/dL) & $0.9(0.7-1.1)$ & $0.8(0.65-1.1)$ & 0.98 \\
\hline Hemoglobin (g/dL) & $11.75( \pm 1.65)$ & $11.83( \pm 2.0)$ & 0.67 \\
\hline Hematocrit (\%) & $35.7(31.5-40.3)$ & $36(31.35-40)$ & 0.99 \\
\hline 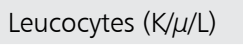 & $8.75(7-11.3)$ & $8.9(7.55-11.85)$ & 0.80 \\
\hline Lymphocytes (\%) & $18.6(15.5-24)$ & $18(13.45-22)$ & 0.27 \\
\hline Urea (mg/dL) & 36.7 (31 - 48.3) & $36.35(29.9-45.45)$ & 0.73 \\
\hline
\end{tabular}

All values, except hemoglobin, are reported with a median and an interquartile range. BUN: blood urea nitrogen.

Table 4. Comparative analysis of clinimetric characteristics of patients with hip fractures with and without depression

\begin{tabular}{|lccr|}
\hline Scales & $\begin{array}{c}\text { With depression } \\
\mathbf{n = 1 4 2 ( 4 6 \% )}\end{array}$ & $\begin{array}{c}\text { Without depression } \\
\mathbf{n = 1 6 8}(\mathbf{5 4 \% )}\end{array}$ & p \\
\hline Insomnia scale & $2.5(0-8)$ & $0(0-5)$ & 0.004 \\
\hline Díaz-Veiga scale & $22(18-25)$ & $24(21-27)$ & $<0.001$ \\
Lawton scale & $3(2-4)$ & $4(3-4)$ & $<.001$ \\
\hline Barthel index & $78(64-90)$ & $89(80-93.5)$ & $<0.001$ \\
\hline Nutritional assessment & $21(19-24)$ & $24(21-26.5)$ & $<0.001$ \\
Visual analogue scale (VAS) & $6(5-7)$ & $5(4-7)$ & 0.004 \\
\hline Number of medications & $3(2-4)$ & $2(1-4)$ & 0.006 \\
\hline
\end{tabular}

All values express a median and an interquartile range. 


\section{Discussion}

As mentioned before, depression is a common condition among elderly patients with a high prevalence. The $45.8 \%$ prevalence found in this study is in keeping with results reported in other studies $^{2,3,25}$. Likewise, Szczerbińska K. et al. ${ }^{26}$ reported twice-higher prevalence in hospitalized OA compared to OA in asylums. In our report, it was observed that subjects with depressive symptoms were ten years older, 81 vs. 71 year-old, which implies that advanced age and hospitalization are factors of strong association with depressive symptoms in OA. On the other hand, the prevalence of women with depression was $79.6 \%$, higher compared to a study conducted in Chile in subjects hospitalized in an internal medicine service, with $28.1 \%$ of female depression ${ }^{27}$. This difference could be to the fact that depression as well as HF is more frequent in women ${ }^{28}$, since women have longer life expectancy.

Another aspect remarkable is the large proportion of patients with diabetes mellitus in the total population, and in the group cataloged with depression. Because $53.9 \%$ of the total were diabetic and had depression, higher than the estimate in the report of Subramaniam M. et al. ${ }^{29}$, who refer a frequency of diabetics by $25.5 \%$ and a $6 \%$ of patients with depression and diabetes. This reflects that diabetes is accompanied by mental alterations, which must be treated all together.

On the other hand, it is interesting to note the possible association between depression and anxiety with insomnia in elderly patients; this is supported by the report of Press et al. ${ }^{30}$, who pointed out that such alterations are more frequent in patients with anxiety than in individuals with depression. Similar results were observed in this report, since patients with anxiety were more frequently found to have these alterations and identified statistically significant differences between groups of patients categorized with and without anxiety $(\mathrm{p}<0.001)$. Also, patients with depression presented a statistically significant difference $(\mathrm{p}=0.004)$, but with lower frequency of patients with depression and insomnia. In contrast to our study, Perlis et al. ${ }^{31}$ observed a higher prevalence of depression in elderly patients with persistent insomnia. Similarly, another study observed that elderly patients with insomnia have a probability of more than $23 \%$ risk of presenting depression $^{32}$. These discrepancies must be grounds for further studies.

Another highlight of the study is the statistically significant difference that was observed in the results of the clinimetric evaluation scales that were applied to patients, which may reflect that in these patients, depression could have occurred before the fracture, in subclinical stages that may still affect the functional results in the elderly patients that are going through HF surgery. This was concluded in a study that refers to the depressive symptoms that arise after a HF and are associated with a decreased functional state and that clinical and psychosocial variables predict the tendency for depressive status ${ }^{33}$. Likewise, Shahab et al. ${ }^{34}$ point out that a routine evaluation with instruments such as the Yesavage scale, can help screen patients at risk of unsatisfactory results in rehabilitation and predict functional results after a HF in OA. It is relevant to consider the results of the evaluation of the MNA, with 80 subjects (56.3\%) with depression and at risk of malnutrition and 20 (14.1\%) with depression plus malnutrition. These results may be associated with the altered state of mind of these patients, resulting in lower nutrient intake, placing them at a risk of malnutrition before being hospitalized, and higher risk of falls due to muscle weakness and causing a possible HF that when resolved by major surgery, they present susceptibility through delayed healing and infections of surgical wound; as observed in the review carried out by Abd Aziz et al. ${ }^{35}$, who reported that infections are more frequent in these patients.

\section{Limitations of the study}

No assessment was requested from psychiatry, which could cause a measurement bias. Although the Yesavage scale is valid and reliable, it is a screening instrument that does not substitute the psychiatric evaluation. A concentration and selection bias was not ruled out since elderly patients hospitalized with HF were studied, with an increase in the prevalence of depression due to functional limitation and pain. Additionally, some patients were abandoned, without an identifiable primary caregiver. Another limitation was the lack of follow-up to the clinimetric evaluation to document changes that occurred after the fracture was treated and to verify if the functionality could be recovered to the levels before the fracture occurred. As it can be observed, there was a difference 
of ten years between the groups of patients which could determine the significant differences in the scales of geriatric assessment. Strengths: Probabilistic sampling was done to temper those possible selection biases. The interviews were blind and independent, and the interviewers were unrelated to the investigation, avoiding courtesy and interviewer biases.

In conclusion, the prevalence of depression was higher in relation to similar studies of hospitalized OA. Patients with depression use a greater number of drugs and diabetes, hypertension, auditory and visual sensorial affections are frequent conditions among patients with depression.

\section{References}

1. Cheng BH, Chen PC, Yang YH, Lee CP, Huang KE, Chen VC. Effects of depression and antidepressant medications on hip fracture: A population-based cohort study in Taiwan. Medicine (Baltimore) 2016; 95: e4655.

2. Taylor WD. Clinical practice. Depression in the elderly. NEJM 2014; 371: 1228-36.

3. Dubljanin Raspopović E, Marić N, Nedeljković U, Ilić N, Tomanović Vujadinović S, Bumbaširević M. Do depressive symptoms on hospital admission impact early functional outcome in elderly patients with hip fracture? Psychogeriatrics 2014; 14: 118-23.

4. Rathbun AM, Shardell M, Orwig D, Gruber-Baldini AL, Ostir G, Hicks GE, et al. Effects of prefracture depressive illness and postfracture depressive symptoms on physical performance After Hip Fracture. J Am Geriatr Soc 2016; 64: e171-6.

5. Brünger M, Spyra K. Prevalence of comorbid depressive symptoms in rehabilitation: a cross-indication, nationwide observational study. J Rehabil Med 2016; 48: 903-8.

6. Akincigil A, Matthews EB. National rates and patterns of depression screening in primary care: results from 2012 and 2013. Psychiatr Serv 2017; 68: 660-6.

7. Xiang X, Brooks J. Correlates of depressive symptoms among homebound and semi-homebound older adults. J Gerontol Soc Work 2017; 60: 201-14.

8. Sotelo-Alonso I, Rojas-Soto JE, Sánchez-Arena C, Irigoyen-Coria A. La depresión en el adulto mayor: una perspectiva clínica y epidemiológica desde el primer nivel de atención. Arch Med Fam 2012; 14: 5-13.

9. Dennis M, Kadri A, Coffey J. Depression in older people in the general hospital: a systematic review of screening instruments. Age Ageing 2012; 41: 148-54.

10. Dhanwal DK, Dennison EM, Harvey NC, Cooper C.
Epidemiology of hip fracture: worldwide geographic variation. Indian J Orthop 2011; 45: 15-22.

11. Avila-Funes JA, Melano-Carranza E, Payette H, Amieva H. Depressive symptoms as a risk factor for dependence in elderly people. Salud Publica Mex 2007; 49: 367-75.

12. Yesavage JA, Brink TL, Rose TL, Lum O, Huang V, Adey $\mathrm{M}$, et al. Development and validation of a geriatric depression screening scale: a preliminary report. J Psychiatr Res 1982-1983; 17: 37-49.

13. Brown LM, Schinka JA. Development and initial validation of a 15-item informant version of the geriatric depression scale. Int J Geriatr Psychiatry 2005; 20: 911-8.

14. Barrón A. Apoyo social. Aspectos teóricos y aplicaciones. Editorial Siglo XXI; Madrid, 1996.

15. Vergara I, Bilbao A, Orive M, García-Gutiérrez S, Navarro G, Quintana JM. Validation of the Spanish version of the Lawton IADL Scale for its application in elderly people. Health Qual Life Outcomes 2012; 10: 130.

16. Ohura T, Hase K, Nakajima Y, Nakayama T. Validity and reliability of a performance evaluation tool based on the modified Barthel Index for stroke patients. BMC Med Res Methodol 2017; 17: 131.

17. Bleda MJ, Bolibar I, Parés R, Salvà A. Reliability of the mini nutritional assessment (MNA) in institutionalized elderly people. J Nutr Health Aging 2002; 6: 134-7.

18. Barber JH, Wallis JB, McKeating E. A postal screening questionnaire in preventive geriatric care. J R Coll Gen Pract 1980; 30: 49-51.

19. Hawker GA, Mian S, Kendzerska T, French M. Measures of adult pain: Visual Analog Scale for Pain (VAS Pain), Numeric Rating Scale for Pain (NRS Pain), McGill Pain Questionnaire (MPQ), Short-Form McGill Pain Questionnaire (SF-MPQ), Chronic Pain Grade Scale (CPGS), Short Form-36 Bodily Pain Scale (SF-36 BPS), and Measure of Intermittent and Constant Osteoarthritis Pain (ICOAP). Arthritis Care Res (Hoboken) 2011; 63 Suppl 11: S240-52.

20. Gagnon C, Bélanger L, Ivers H, Morin CM. Validation of the Insomnia Severity Index in primary care. J Am Board Fam Med 2013; 26: 701-10.

21. Geroff AJ, Olshaker JS. Elder abuse. Emerg Med Clin North Am 2006; 24 (2): 491-505, ix. Review.

22. Bergstrom N, Braden BJ. Predictive validity of the Braden Scale among black and white subjects. Nurs Res 2002; 51 (6): 398-403.

23. Goldberg D, Bridges K, Duncan-Jones P, Grayson D. Detecting anxiety and depression in general medical settings. BMJ 1988; 297: 897-9.

24. Secretaría de Salud de México. Prevención de caídas en pacientes hospitalizados. 1ra Edición. México, D.F; 2010. 
25. Argyropoulos K, Gourzis P, Jelastopulu E. P-721 Depression in older people: prevalence and underdiagnosis in members of day care centers in Patras. Eur Psychiatry 2012; 27: 1 .

26. Szczerbińska K, Hirdes JP, Zyczkowska J. Good news and bad news: depressive symptoms decline and undertreatment increases with age in home care and institutional settings. Am J Geriatr Psychiatry 2012; 20 : 1045-56

27. von Mühlenbrock SF, Gómez DR, GonzálezV M, Rojas AA, Vargas GL, von Mühlenbrock PC. Late life depression prevalence in patients admitted to an Internal Medicine Service. Rev Chil Neuro-Psiquiatr 2011; 49: 331-7.

28. Frederiksen A, Abrahamsen B, Johansen PB, Sørensen HA. Danish, national cross-sectional observational study on the prevalence of prior major osteoporotic fractures in adults presenting with hip fracture-limitations and scope for fracture liaison services in prevention of hip fracture. Osteoporos Int 2018; 29: 109-14.

29. Subramaniam M, Abdin E, Vaingankar JA, Picco L, Seow E, Chua BY, et al. Comorbid diabetes and depression among older adults - prevalence, correlates, disabi- lity and healthcare utilization. Ann Acad Med Singapore 2017; 46: 91-101.

30. Press Y, Punchik B, Freud T. The association between subjectively impaired sleep and symptoms of depression and anxiety in a frail elderly population. Aging Clin Exp Res 2018; 30: 755-65.

31. Perlis ML, Smith LJ, Lyness JM, Matteson SR, Pigeon WR, Jungquist CR, et al. Insomnia as a risk factor for onset of depression in the elderly. Behav Sleep Med 2006; 4: 104-13.

32. Jaussent I, Bouyer J, Ancelin ML, Akbaraly T, Peres K, Ritchie $\mathrm{K}$, et al. Insomnia and daytime sleepiness are risk factors for depressive symptoms in the elderly. Sleep 2011; 34: 1103-10.

33. Cristancho P, Lenze EJ, Avidan MS, Rawson KS. Trajectories of depressive symptoms after hip fracture. Psychol Med 2016; 46: 1413-25.

34. Shahab S, Nicolici DF, Tang A, Katz P, Mah L. Depression predicts functional outcome in geriatric inpatient rehabilitation. Arch Phys Med Rehabil 2017; 98: 500-7.

35. Abd Aziz NAS, Teng NIMF, Abdul Hamid MR, Ismail NH. Assessing the nutritional status of hospitalized elderly. Clin Interv Aging 2017; 12: 1615-25. 